\title{
Narrativas de viagem: escritos autorais que transcendem o tempo e o espaço
}

\author{
Monica Martinez*
}

\begin{abstract}
Resumo
Este trabalho mapeia o universo das narrativas de viagem, de suas origens na literatura e, após a consolidação do jornalismo no século 19, na produção dos jornalistas-escritores que se dedicaram à prática, em particular no livro-reportagem, tendo por base a pesquisa bibliográfica. $\bigcirc$ trabalho objetiva resgatar a trajetória do gênero a partir de Homero (VIII a.C), bem como elencar a produção jornalística contemporânea mais relevante e refletir sobre a modalidade no contexto do Jornalismo Literário e sua ligação com outras áreas do conhecimento, como a etnografia e a antropologia. A principal conclusão deste estudo é a de que esta modalidade tem o potencial de exercer um papel transformador tanto para o produtor quanto para o leitor destas narrativas.
\end{abstract}

Palavras chave: Jornalismo. Jornalismo Literário. Narrativas de Viagem. Pesquisa bibliográfica.

\section{Travel writing: authorial writings that transcend time and space Abstract}

The aim of this paper is to recover the history of travel writing, from its origins in the literature and, after consolidation of journalism in the nineteenth century, in the production of journalists and writers who devoted themselves to the practice, particularly in book form, based on bibliographical resarch. The main topic of this paper is to revive the history of the genre from Homer (VIII BC) as well as to list the most relevant contemporary journalistic production and reflect on the modality in the context of Literary Journalism, as well as its connection with other areas of knowledge, such as ethnography and anthropology. The main conclusion of this study is that this method has the

\footnotetext{
" Professora doutora do curso de Jornalismo, Centro Universitário FIAM-FAAM e do PGCOM, Faculdades Metropolitanas Unidas (FMU) - São Paulo, SP, Brasil. Fez doutorado em Ciências da Comunicação (ECA-USP) e pós-doutorado pelo Programa de Pós-Graduação em Comunicação Social da Universidade Metodista de São Paulo (Póscom/UMESP). E-mail: martinez.monica@uol.com.br.
} 
potential to play a transforming role for both the producer and the reader of such narratives.

Keyword: Journalism. Literary Journalism. Travel Writing. Bibliographical research.

\section{Escrituras de viaje: narraciones que ultrapasan el tiempo y el espacio}

\section{Resumen}

En este trabajo se mapea el universo de los relatos de viaje, desde sus orígenes en la literatura y, después de la consolidación del periodismo en el siglo 19, la producción de los periodistas, escritores que se dedicaron a la práctica, sobre todo en forma de libro, sobre la base de la investigación bibliográfica. La obra tiene como objetivo revivir la historia del género desde Homero (VIII aC), así como destacar la lista de los más relevantes producciónes periodísticas contemporáneas y reflexionar sobre la modalidad en el contexto del periodismo literario. El artículo también enumera las contribuciones periodísticas contemporáneas más relevantes. Por último, en una perspectiva transdisciplinaria, el estudio refleja la modalidad en el contexto del periodismo literario y su relación con otras áreas del conocimiento, tales como la etnografía y la antropología. La principal conclusión de este estudio es que este método tiene el potencial de desempeñar un papel transformador tanto para el productor como para el lector de estos relatos. Palabras clave: Periodismo. Periodismo Literario. Relatos de viaje. Revisión de Literatura.

\section{Breve história e exemplos contemporâneos sobre o tema}

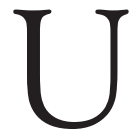

Ta parte valiosa da bagagem trazida por viajantes de todos os tempos se constitui nos relatos das sagas empreendidas pelos quatro cantos do mundo. No âmbito deste tema ainda pouco estudado em jornalismo, seria possível estabelecer a continuidade destas narrativas entre a literatura e o jornalismo? Por meio de pesquisa bibliográfica, este artigo revisa a literatura e mapeia algumas das obras mais importantes que precederam e influenciaram a vigorosa produção contemporânea de narrativas de viagem. $\mathrm{O}$ trabalho objetiva resgatar a trajetória do gênero a partir de Homero (VIII a.C), apontando escritores, missionários, exploradores, cientistas, peregrinos e imigrantes que praticaram essa modalidade literária, bem como 
elencar a produção jornalística contemporânea mais relevante e refletir sobre a modalidade no contexto do chamado Jornalismo Literário e sua ligação com outras áreas do conhecimento, como a etnografia e a antropologia.

Esta viagem jornalístico-literária começa entre os gregos. Devemos a Homero a primeira narrativa de viagem que chega até nós ${ }^{1}$. O poeta grego teria vivido em VIII a.C., justamente no momento em que a escrita nasce na Grécia antiga. Se em Iliada Homero relata a Guerra de Tróia, o primeiro relato de conflito ${ }^{2}$, em Odisseia narra a saga do rei Ulisses para regressar ao seu lar, Ítaca (HOMERO, 2002).

A produção de Homero reflete o pensamento mítico, registrando a coexistência nem sempre harmoniosa de humanos e deuses. Levaria ainda três séculos para que outro grego, Heródoto, registrasse os primeiros relatos baseados em viagens pessoais. Em V a.C., ele escreve Historia, narrativa contínua distribuída em nove livros que conta o crescimento e o ocaso do império persa e as jornadas de Heródoto pelo Egito, Babilônia, Ucrânia, Itália e Sicília (HERÓDOTO, 1964).

A partir desse ponto, a nascente literatura de viagem estaria marcada pela visão de um autor que empreende uma longa jornada com um único ou vários destinos sequenciais. Esse estilo autoral, aliás, é considerado elemento-chave no estudo do Jornalismo Literário, vertente jornalística que se dedica ao estudo das narrativas de viagem, fazendo parte dos estudos do estadunidense Mark Kramer (KRAMER, 1995) e do brasileiro Edvaldo Pereira Lima (LIMA, 2009; MARTINEZ, 2009), entre outros.

Diferentemente da pintura rupestre, cujos códigos de interpretação estão perdidos em muitos casos, as narrativas de viagem pri-

\footnotetext{
${ }^{1}$ Este artigo é uma versão revisada e atualizada do paper apresentado no VII Encontro Nacional de Pesquisadores em Jornalismo, realizado pela SBPJor Associação Brasileira de Pesquisadores em Jornalismo na Universidade de São Paulo em novembro de 2009.

2 Tradução do artigo do jornalista do The New York Times sugere que pesquisadores contemporâneos atribuem as ruínas localizadas no oeste da Turquia como o cenário do cerco realizado no século 13 a.C. In: WILFORD, John Noble. A Tróia de Homero, cercada por polêmica. O Estado de S. Paulo. São Paulo, 27 out 2002, A14.
} 
mam por dois elementos fundamentais: o primeiro é a observação, método que permite vários níveis de aproximação, sendo o mais profundo a observação participante. A resenha da socióloga brasileira Lidia Valladares sobre o livro de William Foote Whyte, Os dez mandamentos da observação participante, traz reflexões valiosas sobre o tema (VALLADARES, 2009). Já o antropólogo da comunicação belga Yves Winkin aponta a relação entre o Jornalismo Literário e as pesquisas etnográficas (WINKIN, 1998, p.134-135).

O segundo elemento importante é a interpretação do material coletado. O filósofo e linguista búlguro Tzvetan Todorov, radicado em Paris desde 1963, contrapõe a noção de sentido à de interpretação. "O sentido (ou a função) de um elemento da obra é sua possibilidade de entrar em correlação com outros elementos desta obra e com a obra inteira" (TODOROV, 1976, p.210).

Por interpretação o atual diretor do Centro de Pesquisa sobre as Artes e a Linguagem de Paris compreende: "interpretação de um elemento da obra é diferente segundo a personalidade do crítico, suas posições ideológicas, segundo a época. Para ser interpretado é incluído em um sistema que não é o da obra, mas o do crítico" (TODOROV, 1976, p.210).

Tomando como exemplo o clássico Madame Bovary, do escritor francês Gustave Flaubert (1821-1880), Todorov sintetiza: "O sentido de Madame Bovary é o de se opor à literatura romântica. "Quanto à sua interpretação, ela varia segundo as épocas e as críticas" (TODOROV, 1976, p.211).

Todorov também chama a atenção para o tempo do discurso: "existe um narrador que relata a história; há diante dele um leitor que a percebe. Neste nível, não são os acontecimentos relatados que contam, mas a maneira pela qual o narrador nos faz conhecê-los (idem).

A percepção do narrador, um observador atento e muitas vezes dotado de habilidade narrativa, é ponto fundamental dos relatos de viagem. Tanto que décadas antes de Todorov o sociológo alemão Walter Benjamim (1892-1940) já chamava atenção para o fato de que a arte de narrar estaria em extinção. Crítico literário da escola de Frankfurt, ele sugere que narrar devidamente é cada vez mais raro. "Quando se pede num grupo que alguém narre alguma 
coisa, o embaraço se generaliza. É como se estivéssemos privados de uma faculdade que nos parecia segura e inalienável: a faculdade de intercambiar experiências" (BENJAMIM, 1994, p.96-197):

A experiência que passa de pessoa a pessoa é a fonte a que recorreram todos os narradores. E, entre as narrativas escritas, as melhores são as que menos se distinguem das histórias orais contadas pelos inúmeros narradores anônimos. Entre estes, existem dois grupos, que se interpenetram de múltiplas maneiras. A figura do narrador só se torna plenamente tangível se temos presentes esses dois grupos. "Quem viaja tem muito que contar", diz o povo, e com isso imagina o narrador como alguém que vem de longe. Mas também escutamos com prazer o homem que ganhou honestamente sua vida sem sair do seu país e que conhece suas histórias e tradições. Se quisermos concretizar esses dois grupos através dos seus representantes arcaicos, podemos dizer que um é exemplificado pelo camponês sedentário, e outro pelo marinheiro comerciante. Na realidade, esses dois estilos de vida produziram de certo modo suas respectivas famílias de narradores. Cada uma delas conservou, no decorrer dos séculos, suas características próprias. (...) No entanto essas duas famílias, como já se disse, constituem apenas tipos fundamentais. A extensão real do reino narrativo, em todo o seu alcance histórico, só pode ser compreendido se levarmos em conta a interpenetração desses dois tipos arcaicos. O sistema corporativo medieval contribuiu especialmente para essa interpenetração. $\mathrm{O}$ mestre sedentário e os aprendizes migrantes trabalhavam juntos na mesma oficina; cada mestre tinha sido um aprendiz ambulante antes de se fixar em sua pátria ou no estrangeiro. Se os camponeses e os marujos foram os primeiros mestres da arte de narrar, foram os artífices que a aperfeiçoaram. No sistema corporativo associava-se o saber das terras distantes, trazidos para casa pelos migrantes, com o saber do passado, recolhido pelo trabalhador sedentário (BENJAMIM, 1994:197-198).

Embora os relatos de aventuras em terras distantes sejam os mais conhecidos, convém lembrar que o mergulho em comunidades próximas feito por etnólogos, antropólogos e jornalistas, também pode em alguma medida ser compreendido como parte desta modalidade de narrativa. As expedições Urbenauta, que o jornalista Eduardo Fenianos empreende na capital paulista, são um exemplo (FENIANOS, 2002) $)^{3}$. Nos estudos de comunicação, outro autor a se destacar é o estadunidense Robert Park (1864-1944), influente pesquisador da Escola de Chicago (CONDE, 2008).

${ }^{3}$ Em 2009, o jornalista paulista Paulo Markun reescreveu a história de Cabeza de Vaca no livro homônimo (Markun, 2009). 
Quanto à natureza da narrativa de viagem, podemos classificá-la em três tipos principais: os relatos ficcionais, os não-ficcionais (escritos a partir de fatos reais, embora os autores possam usar recursos literários para tornar a leitura mais envolvente) e mistos, produtos de ficção inspirados em fatos reais. Uma narrativa de viagem clássica que estaria nesta terceira categoria seria Il Milione, traduzido para o português por o Livro das Maravilhas, As Viagens ou As Viagens de Marco Polo dependendo da editora (POLO, 1999; POLO, 2001). Narrado em 1299 por Marco Polo (1254-1324) ao escritor toscano Rustichello da Pisa, quando ambos estavam presos em Gênova (1298-99), a obra contém a saga do mercador veneziano pela rota da Seda e corte do conquistador mongol Kublai Kan (1215-1294).

Até o Renascimento, a maior parte desses relatos era feita na forma de diários ou cartas de viagem, como a Carta do escrivão Pero Vaz de Caminha (1450-1500), que morreria meses depois de registrar a chegada ao Brasil da esquadra de Pedro Álvares Cabral (CAMINHA, 1998). Os livros do período, edições ricamente ilustradas manuscritas por monges e aprendizes, levavam meses para serem confeccionados, sendo caros e acessíveis a poucos letrados fora dos muros das abadias. A invenção da imprensa pelo alemão Johannes Gutenberg (1390-1468) muda esse quadro, barateando os custos e, assim, ampliando a aquisição de exemplares pela emergente burguesia.

No entanto, os diários e mais tarde, os blogs, continuam uma forma importante de registro não-ficcional. É o caso de Minha Vida de Menina, que preserva um dos poucos relatos do cotidiano mineiro do final do século 19 feitos a partir da ótica de uma adolescente brasileira (MORLEY, 1998).

O fascínio pelas viagens e seus relatos não ocorre apenas no Ocidente. Mestre dos haicais simples e naturais, o poeta japonês Matsuo Bashô (1644-1694) empreende quatro grandes viagens pelo Japão medieval, quando as estradas eram cheias de perigos e o deslocamento uma aventura. Em 1684, ele vai de Edo ao Monte Fuji e Kioto e os poemas produzidos são compilados no livro Account of Exposure to the Fields. Em 1687, viaja ao campo para contemplação da lua e, no ano seguinte, celebra o Ano Novo Lu- 
nar de 1688 em Ueno. Em 1689, vai à Província de Honshu. São 150 dias de viagem, $2.400 \mathrm{~km}$ percorridos e o livro publicado em 1694, The Narrow Road to the Interior (Trilha Estreita ao Confim), mescla narrativas de viagem e poesia (BASHÔ, 1997).

A literatura de viagem viceja em épocas de intenso trânsito social, como ocorre no período das grandes navegações (século 15) e dos grandes Impérios, como o Britânico (século 16 a 19). A ocupação de territórios também mobiliza o trânsito de missionários para evangelizar os povos nativos. No caso do Mercosul, exemplo são as missões construídas pelos jesuítas no século 15 no território então espanhol devido ao Tratado de Tordesilhas, que hoje compreende o sul do Brasil, a Província de Misiones, no Nordeste da Argentina, e o departamento de Misiones, no centro-sul do Paraguai. A Companhia de Jesus, fundada pelo basco Inácio de Loyola (1491-1556), ainda uma das maiores ordens católicas do mundo, empreende um diferenciado sistema de ocupação do território usando não europeus, como mais tarde faria Portugal, mas índios guaranis. A intenção de visitar ruínas e relíquias sacras mais tarde causa o trânsito de peregrinos, como o de Santiago de Compostela, na Espanha, com seus registros literários.

A partir do Renascimento, o hábito de viajar se dissemina também nas elites burguesas, moda que culminará no turismo apressado do século 21:

No início se fazia o Grand Tour clássico, no qual predominavam os aspectos culturais, com visitas a museus, galerias de arte e locais históricos. Em um segundo momento, o principal interesse dos viajantes voltou-se para os amplos cenários naturais, roteiro que se denominou Grand Tour romântico. Porém em ambos os casos entendia-se que a viagem não era apenas de instrução, mas também de lazer. A vida mundana, com todos os seus atrativos, constituía uma espécie de agenda paralela dos jovens endinheirados e também de espíritos maduros, apolíneos (...). A popularização do Grand Tour, a partir do século XVIII, fez proliferar pousadas e hospedarias. Nessa época surgiram também os primeiros relatos de viagem com ampla distribuição na Europa. Esses textos distraíam os leitores, por um lado, e por outro estimulavam ainda mais a mania de viajar (MODERNELL, 2009, p.19).

Essa moda leva à grande aceitação, em ficção, de livros como As Viagens de Gulliver, do autor irlandês Jonathan Swift (1667- 
1745). Como parte de uma elite cultural, os escritores também se rendem à arte do viajar, o que se reflete em sua produção. $\mathrm{O}$ poeta alemão Johann Wolfgang von Goethe (1743-1832) registra suas impressões sobre a Itália em 1816/17, quando escreve Italienische Reise. O escocês Robert Louis Stevenson (1850-1894) é mais conhecido por A Ilha do Tesouro, obra-prima da literatura infanto-juvenil que imprime no imaginário de todas as gerações posteriores o X como o local em que os piratas enterraram o tesouro. Contudo, a primeira obra de Stevenson, Travels with a Donkey in the Cévennes (1879), relata sua viagem de 12 dias pelas montanhas do centro-sul da França. Já The Silverado Squatters (1883) registra a viagem de dois meses de lua-de-mel do escritor com Fanny Vandegrift (e o filho dela, Lloyd Osbourne), pelo Napa Valley, na Califórnia, em 1880.

Em vida, o autor do clássico Moby Dick, Herman Melville (1819-1891), foi mais conhecido por seu primeiro livro, Typee (1846), fruto de sua experiência com os nativos das ilhas Marquesas, na Polinésia francesa, em 1841. O segundo livro desse escritor nova-iorquino, Omoo: A Narrative of the South Seas (1847), aborda sua saga no baleeiro australiano Lucy Ann, quando participa de motim e foge de uma prisão no Taiti.

Muitos exploradores produziram relatos saborosos de suas incursões a lugares distantes. Missionário, Viagens e Pesquisador na África do Sul (1857), do escocês David Livingstone (1813-1873), se tornou um best seller europeu. $\mathrm{O}$ missionário cristão morreria em sua terceira viagem para o continente africano em busca da nascente do rio Nilo, de 1866 a 1873. Antes, porém, o jornalista Henry Stanley vai à Africa encontrar o missionário, que estava perdido. Ao achá-lo, em outubro de 1871 no Lago Tanganika, Stanley profere a famosa frase: "Dr. Livingstone, I presume ?". Stanley supre o explorador com mantimentos e, ao voltar, publica um livro para registrar o feito (How I Found Livingstone in Central Africa). Dentro da tradição de refazer o trajeto de expedições famosas, os passos de Stanley foram dados novamente em 2008 pelo History Channel, agora em formato contemporâneo de reality show.

O explorador norueguês Roald Amundsen (1872-1928), líder da primeira expedição a atingir o Pólo Sul em 1911-1912, relata o 
feito em The South Pole: an account of the Norwegian Antarctic expedition in the Fram. Já a difícil viagem à bordo do Endurance, feita pelo segundo homem a chegar ao pólo sul, é narrada pelo autor, Sir Ernest Henry Shackleton, em Sul (Shackleton, 2002).

Em View from the Summit: The Remarkable Memoir by the First Person to Conquer Everest, o inglês Edmund Hillary narra a primeira escalada do Everest com o sherpa Tenzing Norgay em 1953. Localizado na cordilheira do Himalaia, a montanha mais alta do mundo (Chomolangma em tibetano) fica na fronteira entre o Nepal e o Tibete (ocupado pela China desde 1950).

Cientistas também relatam suas viagens. A mais famosa talvez seja a do naturalista inglês Charles Darwin (1809-1882), que lança Diário e Anotações (Journal and Remarks) sobre sua famosa expedição no HSM Beagle (DARWIN, 1909). Sob o comando do capitão Robert FitzRoy, a empreitada dura três anos a mais do que o previsto (1871 a 1876) e norteia toda a produção científica do então jovem de 22 anos, que vinte anos depois abalaria a comunidade científica ao publicar A Origem das Espécies (1859).

Interessado em comparar o sistema jurídico francês e americano, o pensador político francês Alexis de Tocqueville (1805-1859) viaja aos Estados Unidos no século 19 e descreve minuciosamente o que vê em A Democracia na América, até hoje uma obra de referência sobre o tema (TOCQUEVILLE, 1962).

Da América Latina, De Moto pela América do Sul relata a viagem do revolucionário marxista Ernesto "Che" Guevara em 1952, quando, aos 23 anos e acompanhado pelo amigo Alberto Granado, de 29, deixa a Argentina e percorre oito mil quilômetros pela América do Sul (GUEVARA, 2003). Nos anos 1960, esse tipo de aventura de mochileiros ficaria imortalizado em On the Road, obra do ícone da geração beat estadunidense, Jack Kerouac (19221969), relato inspirado em sua saga de sete anos pela rota 66, que unia o leste ao oeste dos Estados Unidos - hoje ela não faz mais parte do sistema de rodovias norte-americano (KEROUAC, 2004).

$\mathrm{O}$ Brasil não escapa à tendência mundial. No século $15, \mathrm{Em}$ Viagem ao Brasil, o cronista alemão Hans Staden (1525-1579) conta suas duas viagens ao país. Publicado em 1557 em Malburg, o livro torna-se um sucesso (STADEN, 2006). Do mesmo período, o 
explorador espanhol Cabeza de Vaca, primeiro governador de Santa Catarina, conta suas histórias atribuladas, parte delas passadas no Brasil colonial (CABEZA DE VACA, 1999). Grande apreciador de novidades e viagens, o imperador Pedro II registrou em cartas e diário sua ida à exposição de Filadélfia, Estados Unidos (quando o inventor Alexander Graham Bell apresenta o telefone), além de Europa, Egito, Grécia e viagens pelo Brasil (CARVALHO, 2007). Sua última viagem foi a que mais o entristeceu: o exílio para a Europa, após o golpe dado pelos republicanos em 1889.

No século 19, os irmãos Villas Boas participam da marcha para o Oeste (de São Paulo ao atual Mato Grosso) na Expedição Roncador-Xingu realizada em 1943, durante o governo Getúlio Vargas (VILLAS BOAS, 1994). No Brasil no século 20, são conhecidos os livros do navegador Amyr Klink, da família de velejadores Schurmann e do alpinista paranaense Waldemar Niclevicz, entre outros e, no 21, de aventureiros profissionais, como a brasileira Grace Downey (DOWNEY; AGER, 2007).

Sobre a Amazônia, o fenomenal livro-reportagem escrito pelo jornalista americano David Grann resgata de forma vívida a saga do explorador britânico Percy Fawcett pela Amazônia em busca do Eldorado, cidade mítica que ele chamou de Z (GRANN, 2009).

\section{A narrativa de viagem como gênero jornalístico}

Com a consolidação do jornalismo no século 19, muitos jornalistas-escritores publicam em livros-reportagem o excedente de seu material de reportagem ou reflexões sobre suas próprias viagens. Colaborador do jornal Morning Chronicle, o inglês Charles Dickens (1812-1870) critica a América tabagista e escravagista que visita em 1842 no livro American Notes for General Circulation. Mais brando é o relato de sua visita à Itália, em 1846, Pictures from Italy. $\bigcirc$ primeiro livro do jornalista-escritor estadunidense Mark Twain (1835-1910), Innocents Abroad (1869), relata seu cruzeiro pela Europa e Centro Leste pelo jornal Alta California.

Aliás, percebendo o interesse do público pelos relatos de viagem, a mídia teve papel de destaque na divulgação desta modalidade jornalístico-literária. Um exemplo é o jornal New York 
Times. Desde sua compra pelo publisher Adolph Ochs (1858-1935), em 1896 - o jornal havia sido fundado 45 anos antes, em 1851 -, a publicação monta vasta rede de correspondentes internacionais com missão de fazer o diário mais completo do país. Em seu livro sobre a publicação, na qual trabalhou por dez anos, o jornalista estadunidense Gay Talese (2000, p.175) relata que: "o próprio Times patrocinou muitos vôos nos Estados Unidos, bem como vários exploradores, com destaque para o comodoro Robert E. Peary, que descobriu o pólo norte em abril de 1909, e Roald Amundsen, descobridor do pólo sul em dezembro de 1911".

Do mesmo Estado estadunidense, fundada em 1925, a revista The New Yorker também é conhecida por publicar narrativas de viagem de qualidade. Desde 1965, um de seus colaboradores mais admirados é o jornalista e docente da Universidade de Princeton John McPhee. Nascido em 1931, ganhador do Pulitzer de não-ficção de 1999 e apaixonado por geologia, o discreto McPhee não ficou mundialmente conhecido como seus contemporâneos mais performáticos, como Tom Wolfe. Nos Estados Unidos, no entanto, é famoso por seu estilo envolvente e por formar uma geração de jornalistas-escritores, como o atual editor da New Yorker, David Remnick. Uma das suas obras mais conhecidas, Coming into the Country (1977), relata as viagens pelo Alasca e conversas que teve com pilotos, exploradores, colonizadores, políticos e negociantes.

Das revistas, a mais tradicional nesse segmento é a National Geographic Magazine, publicação norte-americana editada desde 1888 pela National Geographic Society. Desde sua fundação, a Society tem patrocinado muitos projetos, como o estudo de chimpanzés da primatóloga britânica Jane Goodall na Tanzânia. Além da New Yorker e da National Geographic, um grande número de revistas em inglês publicam narrativas de viagem de qualidade, como a Esquire, The Atlantic Monthly, Outside, National Geographic Traveler, National Geographic Adventure, Condé Nast Traveler, The Sophisticated Traveler, Salon Travel, Harper's Magazine, Gourmet, Sport's Illustrated, bem como revistas de jornais como The Washington Post Magazine, The New York Times Magazine, além de jornais como o St. Peterburg Times e sites como o Slate.com. 
A revista National Geographic também é editada em português no Brasil e em Portugal. Outra publicação de qualidade no cenário brasileiro é a Revista Viagem e Turismo, da Editora Abril. Com o fechamento da Editora Peixes, em 2009, uma revista tradicional da área, Próxima Viagem, saiu de circulação. Há publicações menores, como a revista Minha Viagem (Editora Cadiz).

A moda de viajar segue em voga e para atender esse público ávido por novidades as narrativas de viagem estão presentes em publicações semanais, de interesse geral, revistas masculinas, femininas e para adolescentes, entre outras, bem como em sites, como o UOL Viagens (http://viagem.uol.com.br), além dos cadernos de turismo de jornais de todo o país, como o Estado de S.Paulo e a Folha de S.Paulo. No caso brasileiro, em geral a qualidade da narrativa de viagem depende pelo menos de dois fatores: a abrangência da linha editorial e a habilidade textual do jornalista.

No segmento de livros, é preciso fazer uma distinção entre guias e livros-reportagem. Os livros-reportagem de viagem (LIMA, 2009), suportes tradicionais do gênero, seguem sendo a principal plataforma qualitativa e quantitativamente, visto que a produção mundial nesse segmento é crescente, embora a maioria dela editada em inglês.

Entre os clássicos estão livros-reportagem feitos a partir de viagens para Paris: em 1933 o jornalista-escritor britânico George Orwell (1903-1950) publica Na pior em Paris e Londres (ORWELL, 2006). De 1964 é a obra póstuma de Ernest Hemingway (1899. 1961), Paris é uma Festa (HEMINGWAY, 1889). A partir dos anos 1990, um grande expoente é o jornalista norte-americano Jon Krakauer, com três de seus quatro títulos publicados em português. Entre eles No Ar Rarefeito, no qual Krakauer conta a tragédia ocorrida em 1996 quando, como jornalista da revista Outside, participa de um grupo que escala o Monte Everest. A expedição termina com oito mortos, entre eles o líder, o neozelandês Rob Hall (KRAKAUER, 1997).

\section{As narrativas de viagem como agentes de transformação}

Esta viagem pela literatura jornalístico-literária sugere que a pergunta que moveu esta pesquisa pode ser respondida de forma 
afirmativa, uma vez que não somente há continuidade, mas também consistência e perenidade nesta modalidade de narrativas. Contudo, este caminho percorrido também sugere novas indagações. Por uma questão de espaço, listaremos três delas apenas, que se aplicam respectivamente a esfera pessoal, social e jornalística desta questão narrativa.

A primeira certamente é de âmbito pessoal. O filósofo francês Giles Lipovetsky lembra que, se a era do individualismo não é invenção recente, ela continua em curso, "colocando o indivíduo livre e igual como valor central de nossa cultura, como fundamento da ordem social e política" (LIPOVETSKY; SERROY, 2011, p.47):

Estamos no momento em que esses fechos de segurança se romperam. Isso constitui a novidade de nosso ciclo cultural. Da mesma maneira que há uma desregulamentação econômica deixando o mercado livre para jogar sua partida com muito menos coerções, o que tradicionalmente funcionava como freio à individualização foi amplamente dissipado. Os valores hedonistas, a oferta sempre mais ampla de consumo e de comunicação, a contracultura convergiram para acarretar a desagregação dos enquadramentos coletivos (família, igreja, partidos políticos, moralismo) e ao mesmo tempo uma multiplicação dos modelos de existência: daí o neoindividualismo do tipo opcional, desregulado, descompartimentado. A "vida a la carte" tornou-se emblemática deste Homo individualis desenquadrado, liberto das imposições coletivas e comunitárias. Na escala da história, é a segunda revolução individualista que está em marcha, instituindo desta vez um indivíduo acabado, extremo: um hiperindividualismo (LIPOVETSKY; SERROY, 2011, p.47-48).

No contexto da sociedade do hiperindivíduo está, portanto, uma das raízes do por que estas narrativas continuarem despertando tanto interesse nos indivíduos. Para o mitólogo Joseph Campbell, idealizador da estrutura narrativa mítica - padrão que encontrou ao estudar contos, sagas, fábulas e mitos de todo o mundo - narrativas como as de viagem simbolizam a aventura da autodescoberta humana (MARTINEZ, 2008). Segundo ele, o objetivo da vida não seria a busca de significado, mas sim a experiência de se estar vivo (CAMPBELL; MOYERS, 1990). E poucas coisas despertam tanto os sentidos quanto sair da zona de conforto, do cotidiano e se lançar em ambientes desconhecidos. Nesse sentido, toda viagem externa é um mergulho interno. Como 
diz em sua tese de doutorado o jornalista-escritor brasileiro Renato Modernell (2009, p.10): "O fato de que ele se move no mundo indica que algo se move dentro dele".

A segunda indagação se trata da inserção das narrativas de viagem contemporâneas no contexto social e histórico. No caso brasileiro em particular, a questão abrange a emergência de uma nova classe média $^{1}$, que não seria medida apenas pelo seu potencial de consumo, mas "pelo sonho de subir na vida. Aonde você vai chegar é mais importante do que de onde você veio e onde está" (NERI, 2011, p.18). Segundo Marcelo Neri, economista-chefe do Centro de Políticas da Fundação Getúlio Vargas, a "carteira de trabalho é o maior símbolo de ascensão como ato consumado, e o concurso público é o seu platônico objeto de desejo" (NERI, 2011, p.19). Entre outros símbolos de status encontram-se certamente as viagens e seus relatos, bem como escolas privadas, planos de saúde e aparatos tecnológicos que permitem, entre outras coisas, o acesso à mídia digital.

Brota, da tensão entre o indivíduo e o coletivo, uma terceira questão: como os relatos dos jornalistas-escritores atuais dialogam com os desafios do mundo contemporâneo:

A situação trágica do mundo moderno, cercado de guerras e violência, o esgotamento crescente do modelo civilizatório que temos, excessivamente calcado na questão econômica, pouco atento às questões sociais, quase nada aberto ao genuíno interesse pelo ser humano, a ignorância escondida por detrás do brilho opaco da inteligência fria sem alma, os enormes ataques da humanidade ao equilíbrio ecológico, tudo isso pede com urgência uma transformação das consciências. Pede uma coragem de rompimento com os modelos reducionistas que nos asfixiam. Pede ação transformadora. $\mathrm{O}$ jornalismo não pode fugir ao seu compromisso com a vida. Tampouco a Literatura da Realidade (LIMA, 2004).

À guisa de consideração final, deixamos uma colocação para ser investigada em pesquisas futuras. A importância da ação dos jornalistas-escritores que escrevem narrativas de viagem talvez transcenda a responsabilidade social. Afinal, a vivência e o relato de realidades e visões de mundo diferentes talvez atraia atenção

${ }^{1}$ O termo, estudado e defendido pela Fundação Getúlio Vargas, não é um consenso entre os economistas, porém foi apropriado e divulgado pela mídia. 
pelo seu potencial de tocar "cordas" profundas nos autores e leitores. É que a produção e leitura de narrativas de viagem de lugares próximos ou distantes desperta no ser humano a sensação ancestral de estar frente ao desconhecido e, com isso, pode mobilizar profundos conteúdos psíquicos que permitem aflorar percepções e inovações até então adormecidas nos indivíduos e na espécie humana (JUNG, 2000). Muitas delas vitais para superar os problemas cada vez mais complexos das sociedades contemporâneas. Como sugere o filósofo judeu de origem austríaca Martin Buber (1878 - 1965), o "homem se torna EU na relação com o TU (BUBER, 2001, p.32). Talvez o principal desafio de nosso tempo continue sendo o mesmo de todos os tempos que nos precederam: aprendermos a nos relacionar de forma mais humana conosco mesmos, entre nós, com a natureza e com o cosmos.

\section{Referências}

BASHÔ, Matsuo. Trilha estreita ao confim. São Paulo: Iluminuras, 1997.

BENJAMIN, Walter. O narrador: considerações sobre a obra de Nikolai Leskov. Magia e técnica, arte e política: ensaios sobre literatura e história da cultura. São Paulo: Brasiliense, 1994. p.197-221.

BUBER, Martin. Eu e tu. São Paulo: Centauro, 2001.

CABEZA DE VACA. Naufrágios e comentários. Porto Alegre: L\&PM, 1999.

CAMINHA, Pero Vaz de. Carta: ao Rei Dom Manuel. Porto Alegre: Mercado Aberto, 1998.

CAMPBELL, Joseph; MOYERS, Bill. O poder do mito. São Paulo: Palas Athena, 1990.

CARVAlHO, José Murilo de. Perfis brasileiros: D. Pedro II. São Paulo: Companhia das Letras, 2007.

CONDE, M. Rosa Berganza. A contribuição de Robert E. Park, o jornalista que se converteu em sociólogo, à teoria da informação. BERGER, Christa; MAROCCO, Beatriz. A era glacial do jornalismo - teorias sociais da imprensa. Porto Alegre: Sulina, 2008. p. 15-32. 
DARWIN, Charles. The voyage of the beagle. New York: P.F. Collier \& Son, 1909.

DOWNEY, Grace; AGER, Robert. Challenging tour dreams: uma aventura pelo mundo. São Paulo: Aleph, 2002.

FENIANOS, Eduardo Emilio. Expedições urbenauta: São Paulo, uma Aventura Radical. São Paulo: Univer Cidade, 2002.

GRANN, David. Z. A cidade perdida: a obsessão mortal do coronel Fawcett em busca do Eldorado brasileiro. São Paulo: Companhia das Letras, 2009.

GUEVARA, Ernesto "Che”. De moto pela América do Sul. São Paulo: Sá Editora, 2003.

HEMINGWAY, Ernest. Paris é uma festa. São Paulo: Círculo do Livro, 1989, 4. ed.

HERÓDOTO. História. Rio de Janeiro: W.M. Jackson, 1964.

HOMERO. Odisséia. São Paulo: Nova Cultural, 2002.

JUNG, C. G. Os Arquétipos e o Inconsciente Coletivo. Rio de Janeiro: Vozes, 2000.

KEROUAK, Jack. On the road. São Paulo: L\&PM, 2004.

KRAKAUER, Jon. No ar rarefeito: um relato da tragédia no Everest em 1996. São Paulo: Companhia das Letras, 1997.

KRAMER, Mark. Breakable rules for literary journalists. In: SIMS, Norman; KRAMER, Mark. (org.). Literary Journalism: a new collection of the best american nonfiction. Nova York: Ballantine Books, 1995. p. 21-34.

LIMA, Edvaldo P. Páginas ampliadas: o livro-reportagem como extensão do jornalismo e da literatura. São Paulo: Manole, 2008.

. Narrativas que inspiram transformação. São Paulo: ABJL, 2004. Disponível em: http://www.abjl.org.br/detalhe.php?conteudo=fl200409071534 $10 \&$ category=ensaios\&lang. Acesso em: 28 set 2004.

LIPOVETSKY, Gilles; SERROY, Jean. A cultura-mundo - resposta a uma sociedade desorientada. São Paulo: Companhia das Letras, 2011. 
MARTINEZ, Monica. Jornada do herói: estrutura narrativa mítica para a construção de histórias de vida em jornalismo. São Paulo: Annablume/Fapesp, 2008.

. O novo capítulo 5: jornalismo com alma. Líbero. Revista do Programa de Pós-Graduação da Fundação Cásper Líbero, São Paulo, ano XI, n. 22, p. 151-152, 2008. Disponível em: http://www.facasper.com.br/pos/libero/ libero_n22.php. Acesso em: 12 jun 2009.

MARKUN, Paulo. Cabeza de vaca. São Paulo: Companhia das Letras, 2009.

MODERNELL, Renato. Em trânsito: um estudo sobre narrativas de viagem. São Paulo: Universidade Presbiteriana Mackenzie, 2009. Tese (Doutorado).

MORLEY, Helena. Minha vida de menina. São Paulo: Companhia das Letras, 1998.

NERI, Marcelo. A nova classe média - o lado brilhante da base da pirâmide. São Paulo: Saraiva, 2011.

ORWELL, George. Na pior em Paris e Londres: a vida de miséria e vagabundagens de um jovem escritor no fim dos anos 1920. São Paulo: Companhia das Letras, 2006.

POLO, Marco. As viagens: il millione. São Paulo: Martin Claret, 2001.

. O livro das maravilhas. Porto Alegre: L\&PM, 1999.

SHACKLETON, Ernest, Sir. Sul: a fantástica viagem do Endurance - a expedição polar mais famosa da história. São Paulo: Alegro, 2002.

STADEN, Hans. Viagem ao Brasil. São Paulo, Martin Claret, 2006.

TALESE, Gay. O reino e o poder: uma história do New York Times. São Paulo: Companhia das Letras, 2000.

TOCQUEVILlE, Alexis de. A democracia na América. Belo Horizonte: Itatiaia, 1962.

TODOROV, Tzvetan. As categorias da narrativa literária. In: BARTHES, Roland. Análise estrutural da narrativa: pesquisas semiológicas. Rio de Janeiro: Vozes, 1976.

VALLADARES, Licia. Os dez mandamentos da observação participante. Revista Brasileira de Ciências Sociais, São Paulo, v. 22, n.63, p. 153-155, 2007. 
Disponível em: $<$ http://www.scielo.br/scielo.php?script=sci_arttext\&pid=S0102$-69092007000100012 \& \operatorname{lng}=$ en\&nrm $=$ iso $>$. ISSN 0102-6909. doi: 10.1590/ S0102-69092007000100012. Acesso em: 22 jul. 2009.

VILLAS Boas, Orlando. Marcha para o oeste. São Paulo: Globo, 1994.

WINKIN, Yves. A Nova Comunicação: da teoria ao trabalho de campo. Campinas: Papirus, 1998.

Recebido em: 17.6.2011

Aceito em: 13.2.2012 